\title{
Towards direct evidence of the effects of salmon lice (Lepeophtheirus salmonis Krøyer) on sea trout (Salmo trutta L.) in their natural habitat: proof of concept for a new combination of methods
}

\author{
R. M. Serra-Llinares $(\mathbb{D} \cdot$ C. Freitas $~ R$ R. Nilsen • \\ K. M. S. Elvik • J. Albretsen • T. Bøhn • Ø. Karlsen • \\ P. A. Bjørn
}

Received: 26 March 2018 / Accepted: 14 September 2018 /Published online: 25 September 2018

(C) The Author(s) 2018

\begin{abstract}
Studies addressing the impact of salmon lice (Lepeophtheirus salmonis Krøyer) on sea trout in their natural habitat are scarce and mostly limited to prophylaxis-based experiments. The main drawbacks with this approach are that lice infestations on control fish are not known and the anti-parasitic treatment is of unknown efficacy and may have unwanted side-effects. We tested an innovative approach where prophylaxis is replaced with artificial infestation of the fish. Twenty-nine sea trout post-smolts were caught in a farming-free area in southern Norway and half the fish were artificially infested with lice. Survival and behavior of individual fish was investigated using acoustic telemetry. Furthermore, salinity values were extracted from an hydrodynamical model simulation and connected to individual 3D positions. Results from this pilot study show consistent trends in
\end{abstract}

Electronic supplementary material The online version of this article (https://doi.org/10.1007/s10641-018-0816-1) contains supplementary material, which is available to authorized users.

R. M. Serra-Llinares $(\varangle) \cdot$ R. Nilsen $\cdot$ K. M. S. Elvik •

J. Albretsen • T. Bøhn • Ø. Karlsen • P. A. Bjørn

Institute of Marine Research, P.O. Box 1870 Nordnes,

5817 Bergen, Norway

e-mail: rosa.maria.serra.1linares@hi.no

C. Freitas

Oceanic Observatory of Madeira, Edifício Madeira Tecnopolo,

Piso 0, Caminho da Penteada, 9020-105 Funchal, Madeira,

Portugal behavioral differences between artificially infested and control fish. All fish that died or prematurely returned to freshwater were artificially infested fish, although results were not statistically significant. Besides, power analysis confirmed the limitations of this small pilot study for delivering statistically significant inferences. We found also indications of artificially infested fish remaining in shallower waters and within shorter distance to low salinity habitats, but only differences in modelled salinity values were statistically significant. Methodological progress and limitations with this original approach are discussed, and we recommend further studies using this combination of methods and the lessons learnt from this pilot study to provide better quantitative evidence on the effect of salmon lice on sea trout in the wild.

Keywords Salmon lice $\cdot$ Sea trout $\cdot$ Artificial infestation $\cdot$ Survival $\cdot$ Behavior $\cdot$ Acoustic telemetry

\section{Introduction}

Salmon farming has experienced a very rapid development in Norway, from a production of a few hundred tons in the early 70's to more than 1.3 million tons in 2015 (Statistics Norway, https://www.ssb.no). There are currently close to 1000 salmon farms scattered along most of the Norwegian coastline, and only a few areas remain free from intensive farming (Directorate of Fisheries, www.fiskeridir.no). The growth of this 
industry has not been without environmental concerns. Together with escaped salmon, the spread of the parasitic copepod salmon louse (Lepeophtheirus salmonis, Krøyer) from fish farms has been identified as a major threat for wild salmonids in Norway (Costello 2009; Taranger et al. 2015; Forseth et al. 2017). Amongst salmonids, sea trout may be particularly vulnerable to salmon lice infestation because most sea trout remain in fjords and coastal waters, where salmon farms -and thus salmon lice- concentrate, during most part of their marine migration. Although the causal relationship between salmon farming and lice epizootics on sea trout has been controversial over the last decade, there is extensive evidence linking high lice infestations on wild sea trout to farm-intensive areas (Bjørn et al. 2001; Bjørn et al. 2011; Middlemas et al. 2013; SerraLlinares et al. 2014; Serra-Llinares et al. 2016; Shephard et al. 2016). Furthermore, it has recently been documented that lice collected from wild salmonids in farm-dense areas often carry resistance to organophosphates in a frequency that mimics those in nearby farms, unequivocally demonstrating that salmon farms are a primary driver of the salmon louse infection dynamics (Fjørtoft et al. 2017).

Salmon lice feeds on skin, blood and mucus of salmonid fish and their harmful effects on individual sea trout have been widely documented. These include osmoregulatory problems and physiological stress responses, secondary infections, reduced fitness and in worst cases a complete physiological breakdown and death of the salmonid host (Birkeland and Jakobsen 1997; Bjorn and Finstad 1997; Dawson 1998; Poole et al. 2000; Bjørn et al. 2001). Changes in migratory behavior (Birkeland 1996; Birkeland and Jakobsen 1997; Bjørn et al. 2001; Gjelland et al. 2014; HattonEllis et al. 2006; Pert et al. 2009) and reduction of marine growth of individual fish (Birkeland 1996; Poole et al. 1996; Butler and Walker 2006; Fjørtoft et al. 2014) have also been documented. Salmon lice in areas with high farming intensity may also negatively impact sea trout on the population level, as shown in Ireland (Tully and Whelan 1993; Tully et al. 1999; Gargan et al. 2003, 2006, 2016), Scotland (Butler and Walker 2006) and Norway (Bjørn et al. 2001; Skaala et al. 2014). Most of this evidence is, however, circumstantial. Direct and quantitative evidence of the relative role of salmon lice infestation on these population declines is still missing. In a recent and extensive review of available scientific literature on the impact of salmon lice on sea trout, Thorstad et al. (2015) concluded that "the most important knowledge gaps are related to salmon lice impacts at the population level and in quantifying the reduction in wild sea trout populations arising from increased mortality and reduced growth attributable to salmon lice".

Disentangling the relative role of salmon lice from other factors regulating mortality and fitness on wild fish, such as food availability, predation, water quality and/or other parasites, is a challenging task, especially since these factors may affect each other in many possible ways. Additionally, free-swimming sea trout may modify their natural behavior to mitigate the effect of the parasites by prematurely returning to freshwater. This behavioral adaptation may mask, delay or prevent direct mortality, but at the cost of reduced marine growth, reduced fecundity and/or reduced spawning success (Birkeland 1996; Birkeland and Jakobsen 1997; Dawson 1998; Gjelland et al. 2014; Shephard et al. 2016; Halttunen et al. 2018), which may ultimately have an impact on the population level. Due to this complexity, field experiments where lice-infested fish can interact with their natural environments are needed to properly measure the relative impact of salmon lice on sea trout at both individual and population levels.

Field studies performing paired releases of control groups and groups treated with an anti-parasitic agent, i.e. prophylaxis-based "randomized control trials", (RCTs), have become a widespread method to disentangle the effect of salmon lice from other factors regulating mortality and growth of wild fish. This approach has been extensively used in recent years to study the impact of salmon lice on the marine survival of Atlantic salmon, estimated through recapture of returning fish (Jackson et al. 2011; Gargan et al. 2012; Krkošek et al. 2013; Skilbrei et al. 2013; Vollset et al. 2014, 2016), whilst very few similar studies have addressed the effect of salmon lice on sea trout (Gjelland et al. 2014; Skaala et al. 2014; Halttunen et al. 2018). However, and despite the potential of RCTs to provide a more accurate picture of the effect of salmon lice on wild fish compared to laboratory studies, there are some caveats associated with the prophylaxis-based approach. Firstly, there may be limitations in the protection provided by the treatment (in terms of efficacy, variation and duration). Secondly, there may be negative effects 
associated with the use of the prophylaxis itself (e.g., toxicity). Finally, prophylaxis-based studies rely on the "natural" lice infestation pressure in the study area which, in most intensively-farmed areas, has been proved to be highly variable and difficult to predict (Serra-Llinares et al. 2014; Helland et al. 2015; SerraLlinares et al. 2016). This, in combination with the typically skewed distribution of lice between wild hosts, makes it very difficult to make inference on the actual lice load in non-protected (control) fish. A more detailed discussion on the limitations of prophylaxis-based RCTs can be found at Vollset et al. (2018) and at Thorstad et al. (2015).

An alternative approach to prophylaxis-based RCTs are studies based on artificial infestation of individual fish with salmon lice and comparison to an un-infested control group in a lice-free area. Such "infestation-based RCTs" may be more suitable for assessing the effect of salmon lice on wild salmonids, as they 1) don't rely on the sustained effect of a prophylactic drug, 2) allow for a better control on the actual lice load on the fish, and 3) no other secondary effects are expected associated with the treatment (artificial infestation). Furthermore, in areas where the lice density is low, this method may also be the only way to conduct a treatment-control experiment.

In this pilot study, we tested the feasibility of an infestation-based RCT to study the effects of salmon lice on the survival and behavior of wild sea trout in their natural habitat. We combined this approach with the use of acoustic telemetry, which allows direct observation of survival of tagged individuals (thus reducing the dependency on the recapture of returning fish) as well as other potential behavioral changes motivated by lice. Finally, we combined 3D fish positions provided by acoustic telemetry with salinity estimates provided by a hydrodynamical model, so that differences in salinity preferences other than premature return to freshwater could be studied. Although we tested this new approach in a pilot study, with a limited number of fish included, we hypothesized that artificially infested fish would be stressed by their parasite load (compared to the control group) and alter their habitat choice seeking for lower salinities. We also hypothesize that the stress caused by the lice would lead to premature returns to freshwater and/or to an increased mortality risk. However, the main goal of this pilot study was to test 1 ) whether this combination of methods was feasible for a field study, and 2) whether there was indication of an added value on this shift in method (from prophylaxis- to infestation-based studies).

\section{Methods}

Study area

The study took place in Sandnesfjord, Southern Norway $\left(58.6943^{\circ} \mathrm{N}, 9.1488^{\circ} \mathrm{E}\right)$ (Fig. 1) from June to September 2016. The closest active salmon farm is situated more than $85 \mathrm{~km}$ away (sea-way distance) from Sandnesfjord, and sustained low lice levels have been recorded on wild sea trout in the area in recent years (Serra-Llinares et al. 2014). The river Storelva runs out to Sandnesfjord, and provides a $20 \mathrm{~km}$ river stretch for anadromous fish. The salinity in Sandnesfjord is commonly above 20, but the inner part of the fjord can be influenced by a shallow layer of fresh or brackish water. The transition areas between Sandnesfjord and the river Storelva, i.e. the areas known as Songevatn and Nævestadfjord, (Fig. 1) are characterized by low salinities, which vary between 0 and 15 depending on depth and the volume of inland freshwater inflow from the Skagerrak and the coastal current (Tjomsland and Kroglund 2010). The whole area between the Nævestadfjord outlet and all the way up to the river Storelva will be referred to as "freshwater" from this point for simplicity.

Fish tagging and artificial infestation

Sea trout post-smolts $(n=36$, size range $40-156 \mathrm{~g})$ were caught in mid-June in Sandnesfjord using fishing traps designed for live sampling of sea trout (Barlaup et al. 2013) (Table 1). Of these, 29 fish were tagged using acoustic tags from Thelma Biotel (ADT-LP-7.3 model, size of $22 \times$ $7.3 \mathrm{~mm} ; 1.1 \mathrm{~g}$ in water; typical battery life of 5 months) following standard chirurgical procedure, as described in Serra-Llinares et al. (2013). Tags were built with a depth sensor $(0.2 \mathrm{~m}$ resolution and $51 \mathrm{~m}$ maximum depth) and programmed to emit a unique identification code at random intervals every 30 to $90 \mathrm{~s}$. The fish were inspected 


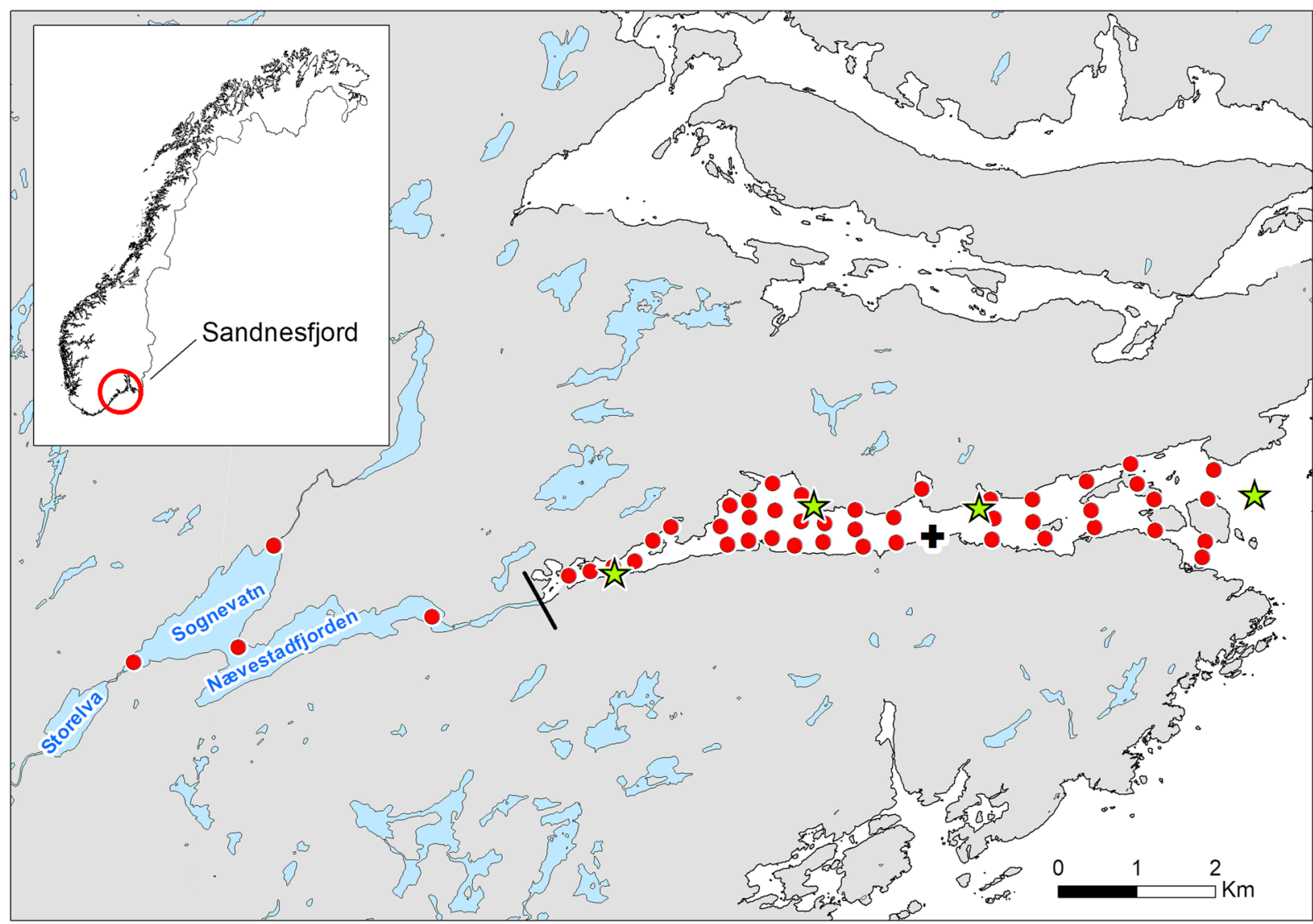

Fig. 1 Sandnesfjord, Southern Norway. Red dots show the configuration of the acoustic hydrophones array. Green stars indicate the position of the DST tags (1 to 4 from East to West). Black cross indicates the position of the release site. The solid black line indicates the limit between sea water (white) and freshwater (light-blue) areas for lice (counts) and randomly assigned to group: "control" $(n=14)$ or "infested" $(n=15)$. The remaining seven fish were tagged with passive dummy tags of the same size and weight as the ADTLP-7.3 tags. This "reference" group was used to evaluate the success of the artificial lice infestation and the recovery after tagging.

Salmon lice copepodids used for artificial infestation were supplied by the Institute of Marine Research in Bergen. First, 40 mature egg strings were collected from female lice ("LsGulen" family, 30/31 generation in the laboratory). After incubation at $9.5{ }^{\circ} \mathrm{C}$ for 10 days, approximately 4000 copepodids were collected and transferred in a $2000 \mathrm{ml}$ thermos bottle to the field site in Sandnesfjord. The procedure of incubation and quantitative assessment is described in Hamre et al. (2009).

For artificial infestation, sea water (salinity 30, $15^{\circ} \mathrm{C}$ ) from $15 \mathrm{~m}$ depth was pumped and circulated into the infestation tank, where fish from both the artificially infested and reference groups were exposed to approximately 180 newly hatched copepodids each. During infestation, water circulation in the tank was stopped and the level kept at approximately $10 \mathrm{~cm}$ for $30 \mathrm{~min}$; oxygen content was continuously monitored and regulated during the process. After infestation, the water circulation was re-established in the tanks, where the fish could recover for $5 \mathrm{~h}$. To avoid a handling effect, the "control" group received a sham infestation following the same procedure as infested fish. After recovery, all fish in the artificially infested and control groups where simultaneously released in the middle part of the fjord (see Fig. 1 for exact position of the release site). Fish in the reference group were transferred to a nylon net recovery cage (volume $0.5 \mathrm{~m}^{3}$ ) and kept for another $48 \mathrm{~h}$ prior to sampling. 


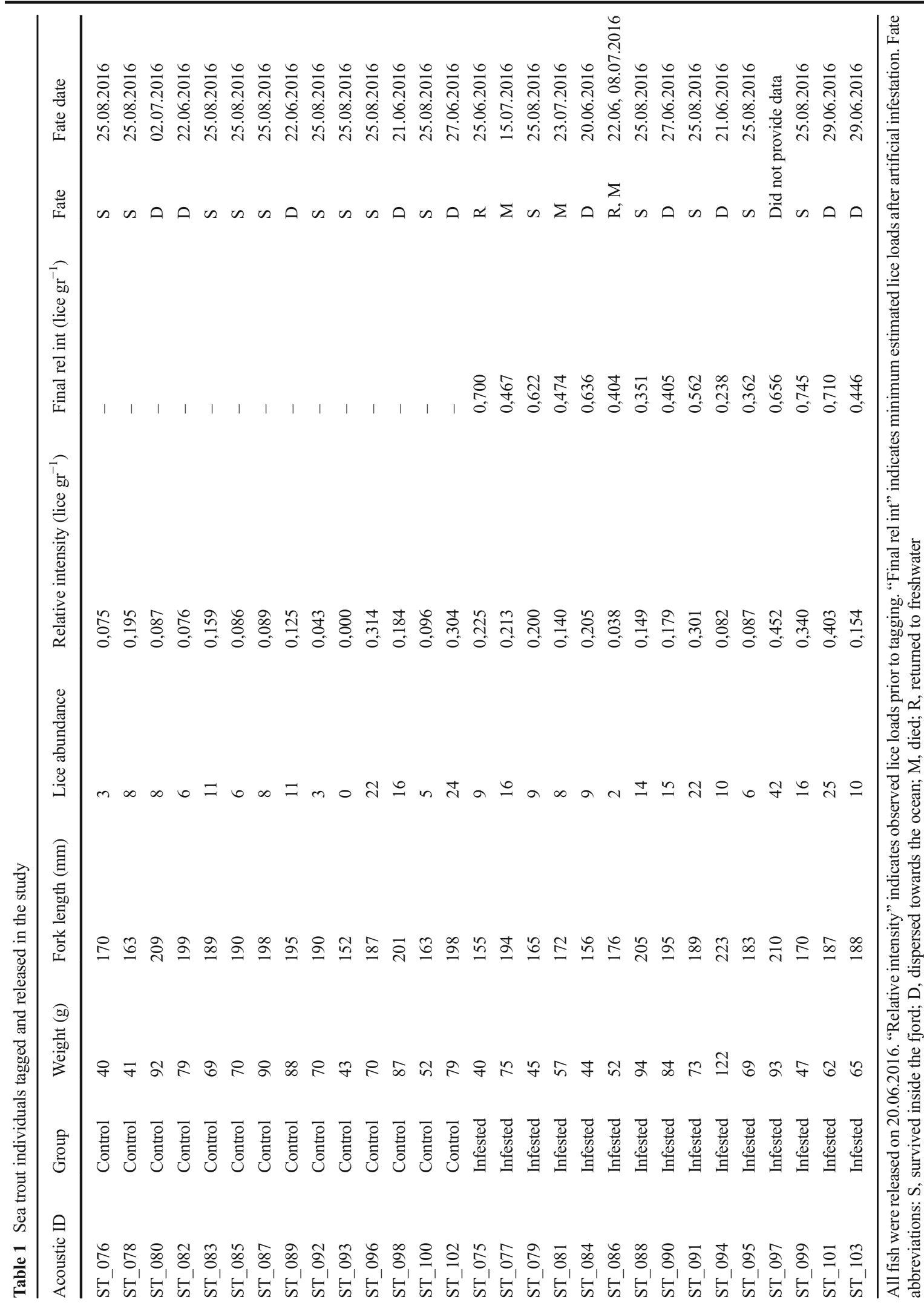


Acoustic tracking of the fish

Tagged fish were monitored from release (20th June) to the end of the study (25th August) through an array of hydrophones (Vemco VR2W) covering the study area both at sea and in freshwater. Range tests indicated an optimal detection range of $150-200 \mathrm{~m}$ in sea water $(85 \%$ of the signals were still picked up by the hydrophones at this distance). Based on this, we designed a hydrophone array consisting of 56 receivers, of which 51 were placed at sea water and five in freshwater (Fig. 1). The array was designed so that it would provide the best possible coverage of the inner part of the fjord, covering the possibility that infested fish would search for a freshwater refuge for delousing. Fish movements in the fjord were monitored using parallel lines of receivers, so that we could assess which part of the fjord (inner/ middle/outer) the fish were at any time. Migration out of the fjord was monitored by a double fence of receivers at the fjord mouth, so that the direction of the fish passing by this area could be assessed. Last, receivers situated in freshwater provided information on the timing and frequency of returns.

The hydrophones recorded the depth and ID information emitted by the fish tags. Data were downloaded from the hydrophones at the end of the study and imported to Vemco VUE software (version 2.2.2). Data were corrected for temporal drift using VUE, and then exported to R software ( $\mathrm{R}$ Core team 2015) where all analyses were performed. Any single isolated detection occurring in a $24 \mathrm{~h}$ period was removed as potentially spurious. Fish positions ( $1 \mathrm{~h}$ intervals) were estimated using center-of-activity locations (Simpfendorfer et al. 2002). The center-of-activity location for a given time interval $t$ is the mean position of the hydrophones that detected the animal at that time interval, weighted by the number of times the animal was detected at each hydrophone (see Simpfendorfer et al. 2002). A mean depth value was also associated to each center-of-activity position, so that they consisted of a $3 \mathrm{D}$ position with latitude, longitude and depth.

Environmental monitoring

Salinity data were obtained for each 3D fish position from a hydro-dynamical model simulation using ROMS (Regional Ocean Modeling System, http://myroms.org) with $50 \mathrm{~m}$ horizontal resolution based on output from NorKyst800 (Albretsen et al. 2011) and a $160 \mathrm{~m}$ model for the southeastern Norwegian coast (similar set ups as conducted in Asplin et al. (2014) and Espeland et al. (2015). All three models applied high-resolution atmospheric forcing from the non-hydrostatic $2.5 \mathrm{~km}$ AROME MetCoOp regional atmospheric model (Müller et al. 2015) provided by the Norwegian Meteorological Institute. The freshwater discharge from Storelva was supplied outside the narrow strait between the Nævestadfjord and Sandnesfjord, and volume fluxes for all rivers were based on daily estimates from the Norwegian Water Resources and Energy Directorate. For model validation purposes, salinity was continuously monitored during the study at four different points along the fjord using DST tags (Star-Oddi, Iceland) (see Fig. 1 for exact positions of the loggers). Measurements from repeated CTD casts were also used to correct the model output for bias. The DST tags deployed near the surface along the fjord revealed that the hydro-dynamic model predicted higher salinity than direct measurements (positive bias) in the surface layer. This is probably attributed to how well defined the river outflow from Storelva is and/or how the vertical river outflow is implemented in the model. A similar bias was found for surface waters, also along the fjord axis (Fig. S1, electronic appendix). However, the model error in salinity was reduced linearly and were close to zero by $22 \mathrm{~m}$ depth. To estimate a more precise salinity level for all tagged fish in the entire Sandnesfjord, we applied a linear relation for salinity bias correction with depth:

$\mathrm{S}_{\text {corrected }}=\mathrm{S}_{\text {model }}-\left(-0.1776^{*} \mathrm{D}+4.0903\right)$, for depths $(\mathrm{D})$ above or equal to $22 \mathrm{~m}$

$\mathrm{S}_{\text {corrected }}=\mathrm{S}_{\text {model }}$, for depths below $22 \mathrm{~m}$ 
The corrected salinity values were used in all further statistical analysis.

Data interpretation and statistical analysis

\section{Fate assessment}

The fate of each individual fish was assessed from their depth profiles and positions. Individuals were classified as: 1) returned to freshwater (moved beyond the Nævestadfjord outlet and did not reenter the fjord), 2) dispersed (last detection crossing the outer double-fence of receivers), 3) dead (either stopped transmitting while inside the study area or started transmitting continuously at the same depth), or 4) survived (detections indicating normal vertical and horizontal swimming activity in the fjord by the end of the study).

\section{Survival and premature return to freshwater}

Cox proportional hazard models (Coxph) were used to analyse potential differences in the probability of survival and of premature return to freshwater between control and infested fish. Coxph models estimate the likelihood that an event will occur at time t. When modelling survival and premature return to freshwater, the fate/status was set as 0 (survived/did not return to river), or 1 (died/returned to river). Fate time was the number of days after release. For fish with fate/status $=0$ (i.e. survived/did not return to river) fate date $(t)$ was defined by the last observation and specified as right-censored data. Group (infested/control) and fish length (fork length) were used as explanatory variables. Models were fitted using the $\mathrm{R}$ library survival.

To further investigate the ability of our approach to detect between-groups differences in survival and premature return under different scenarios, we performed power analysis using the function ssizeCT from the $\mathrm{R}$ library powerSurvEpi. This function allows for sample size calculation for the comparison of survival curves between two groups under the Cox ProportionalHazards Model. Some parameters, such as postulated hazard ratio $(R R)$, power (i.e. power to detect the magnitude of the hazard ratio as small as that specified by $R R$ ), alpha (i.e. type I error rate) or the ratio of participants in each group $(k)$ can be manually adjusted in the function. Other parameters, such as the expected total number of events in each group, are estimated based on a pilot data set. We performed scenario testing to estimate the minimum sample required to detected different hazard ratios $(R R)$ under the premise of three fixed parameters: power $=0.8$, alpha $=0.05$ and $k=1$ (i.e. minimum sample size to have an $80 \%$ probability of detecting a survival ratio $R R$ with a confidence of $95 \%$, and given that there are the same number of fish in both groups).

\section{Habitat choice}

Both distance to freshwater and swimming depth were used as indirect indicators of salinity. The distance to freshwater were estimated as the linear distance between the center of activity (for each individual fish) and the Nævestadfjorden outlet (Fig. 1). Negative distances were assigned to positions beyond this point. Daily mean distance to freshwater was then calculated for each fish. Mean daily swimming depth and mean daily salinity (obtained from the hydro-dynamical model) were also obtained for each fish.

Differences in distance to freshwater, swimming depth and salinity preferences between control and infested fish were tested using linear mixed models. Daily means were used as response variables, while group and fork length were used as explanatory variables. Individual identification was used as random intercept to account for random variation between individuals. An autoregressive process of order 1, corAR1 (see Zuur et al. 2009), was added to the random structure of the model to take temporal autocorrelation into account. Since the hydro-dynamical model did not cover the locations in low salinity areas, i.e. in Songevatn and Nævestadfjord, we fitted two different models for salinity: one model using all fish, where fish in freshwater locations were given a salinity value of zero (to test differences in salinity used in general), and one model where fish in freshwater locations were taken out of the data set (to look at differences in salinity used while inside the fjord only). Models were fitted using the R library nlme. All models were validated following Zuur et al. (2009) to verify that the underlying statistical assumptions were not violated. 


\section{Results}

Initial and artificial lice infestation

Initial inspection of the sea trout post-smolts used in this study, i.e. directly after capture at sea, showed that $96 \%$ of the fish were infested with lice, with infestations ranging from two to 42 lice per fish, corresponding to 0.038 to 0.45 lice per gram fish weight (Table 1). Chalimus II and pre-adult were the predominant stages. After artificial infestation, fish in the "reference" group (artificially infested) had acquired new copepodites, with a mean added intensity of 33 lice per fish. The minimum increase in observed lice on reference fish was 19 copepodites; we used this number to conservatively estimate the minimum final infestation on artificially infested fish ("infested" group), which were then estimated to have post-infestation lice loads ranging from 21 to 61 lice, corresponding to final relative intensities of 0.24 to 0.74 lice $\mathrm{gr}^{-1}$ (Table 1).

Acoustic tracking and fate assessment

A total of 28 fish (14 control and 14 infected) provided depth and movement data (one fish did not provide any data) (Table 1). Most individuals were observed inside the fjord or dispersed towards the ocean. Approximately $1 / 3$ (nine of 28) of the fish left the study area within the first week after release and were never observed again, thus providing limited data for posterior analysis.

\section{Return to freshwater}

All sea trout that returned to freshwater during the study period (two of 28 individuals) were artificially infested fish, but the difference between the groups was not statistically significant ( $p=0,999$; Table 2$)$. Returning fish tended to be small sized ( $p=0,145$; Table 2$)$.

\section{Survival}

Three individuals died during the study period, all belonging to the infested group. However, survival analysis showed no statistically significant difference between the groups ( $p=0,999$; Table 2, Fig. 2). Fish length did not significantly affect the probability of death ( $p=0,896$; Table 2).
Power analysis

Results from the power analysis showed, based on the structure of the data provided by our pilot study (i.e. frequency of events and distribution of censoring points), that a sample size as low as that in the present study (14 fish in each group) would only have the sufficient power to detect significant differences in survival and/or premature return to freshwater between control and artificially infested fish given the survival (or return) ratio $(R R)$ was higher than 10 (i.e. if fish in the control group had a 10 times higher probability of survival/premature return than artificially infested fish) (Table 3). Conversely, to detect small differences in survival/premature return, such as $R R=1.5$, the minimum required sample size would be as high as 2198 fish (1099 fish in each group).

Distance to freshwater

Sea trout made use of the entire fjord, and were also located up to $5.3 \mathrm{~km}$ up from the Nævestadfjorden outlet (Fig. 3). The distance to freshwater (defined as the distance to the Nævestadfjorden outlet; Fig. 1) increased significantly with body size ( $p<0.001$, Fig. 4 , Table 4$)$. The mean daily distance to freshwater was shorter for infested fish $(4.0 \mathrm{~km})$ compared to the control group $(4.9 \mathrm{~km})$ but the difference was not significant $(p=$ 0.136; Table 4, Figs. 3 and 4).

Depth use

Sea trout were in general located close to the surface. Average daily depth ranged between 0.2 and $3.8 \mathrm{~m}$ (Fig. 4). Artificially infested fish were located marginally closer to the surface (average daily depth $=1.1 \mathrm{~m}$ ) compared to non-infected fish (average daily depth $=1.3 \mathrm{~m}$ ) ( $p=0.053$; Fig. 4, Table 4). Average daily depth increased significantly with body size for both groups, showing that larger fish in general used deeper waters ( $p=0,013$; Fig. 4, Table 4).

\section{Salinity}

Average daily salinity used by sea trout varied between 0 and 27.6 (Fig. 4). Results from linear mixed models showed that, while in the Sandnesfjord, trout in the artificially infested group remained in water with significantly lower salinity compared to their counterparts in 
Table 2 Results of the Cox proportional hazard models, modelling the probability of returning to freshwater and the probability of dying at time $t$ as a function of treatment group (untreated vs artificially infested) and body size (fork length, FL)

\begin{tabular}{lllllll}
\hline Event & Covariate & $\beta$ & $\exp (\beta)$ & $\operatorname{se}(\beta)$ & $\mathrm{z}$ & \multicolumn{2}{c}{$P$} \\
\hline Returnal to freswater & Group [Infested] & 21,24 & $1,676,000,000$ & 26,050 & 0.00 \\
& Length & -0.09 & 0.92 & 0,06 & -1.46 & 0.145 \\
Mortality & Group [Infested] & 21.52 & $2,220,000,000$ & 23,570 & 0.00 & 0.999 \\
& Length & -0.01 & 0.99 & 0,04 & -0.13 \\
\hline
\end{tabular}

the control group, although the difference was small (salinity 20 versus 21, $p=0.009$; Table 4, Fig. 4). The preference for higher salinity increased significantly with body size ( $p=0.002$; Table 4$)$.

\section{Discussion}

Salmon lice and its impact on wild fish populations are sources of intense debate in all salmon producing countries, and it is currently of high political and economic relevance in Norway. Solid science-based advice is therefore needed by decision makers to be able to apply sound management strategies. Given the complexity of the systems, coupled with methodological challenges, direct quantitative evidence of the impact of salmon lice on the survival and growth of sea trout in their natural habitat have been proved difficult to obtain. A study by Skaala et al. (2014) in an intensively farmed fjord in western Norway showed that the survival of sea trout smolts treated with an anti-parasitic drug was nearly double compared to a control group. However, overall survival in this study was very low, and the number of surviving fish were limited. In the same fjord, Gjelland et al. (2014) and Halttunen et al. (2018) combined the administration of anti-parasitic treatments with the use of acoustic telemetry to study the survival and migratory behavior of wild, free-swimming sea trout. Despite most of the sea trout tracked in these studies adopted a movement pattern expected to suppress or alleviate salmon
Fig. 2 Survival curves, showing the probability of survival of sea trout (Salmo trutta) post-smolts as a function of treatment group (control, $n=14$ vs infested, $n=14$ )

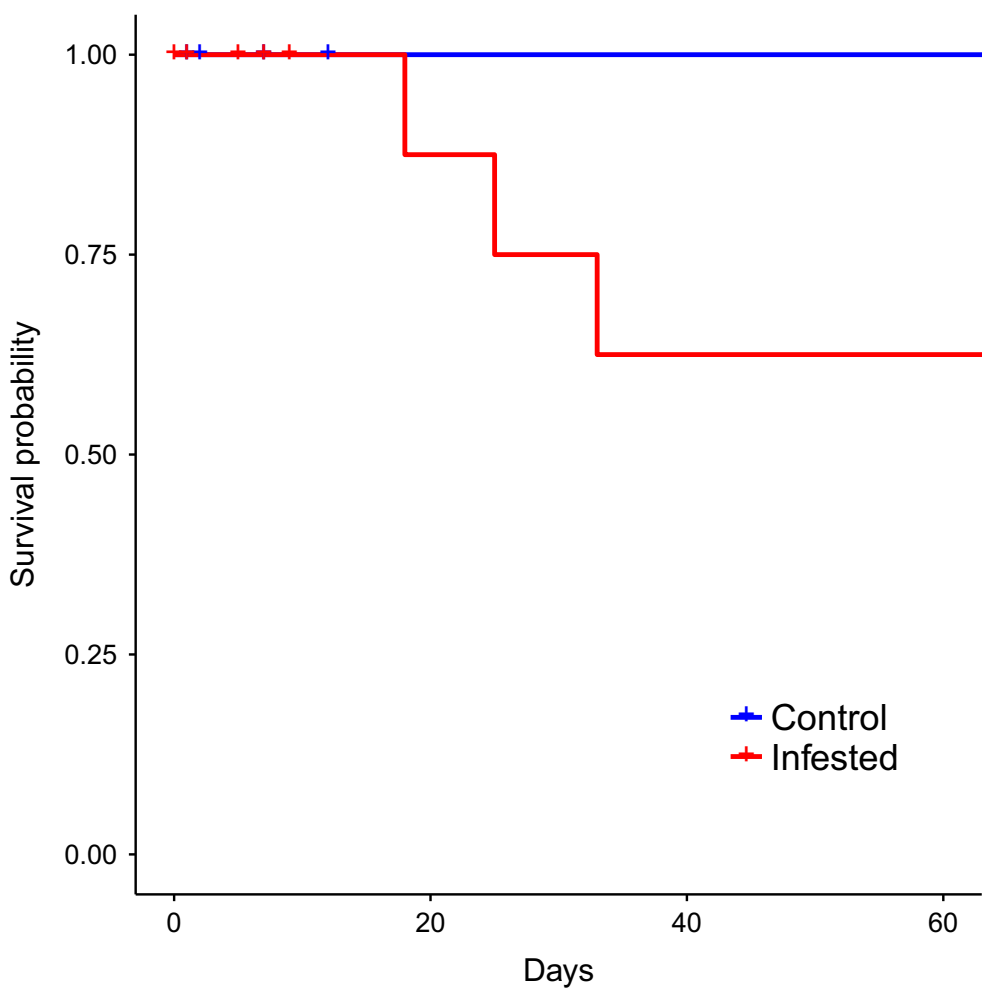


Table 3 Estimated minimum sample sizes (control + experimental group) needed to have an $80 \%$ probability (i.e. power $=0.8$ ) to detect statistical differences in survival/premature return between infested and control fish (survival ratio, RR), with a confidence of $95 \%$ (i.e. alpha $=0.05$ ), given that there are the same number of fish in both groups $(k=1)$

All estimates are based on results from our pilot study and performed using the function ssizeCT from the R library powerSurvEpi

lice infestation, showing a strong preference for fresh and brackish water especially in high exposure years (Gjelland et al. 2014; Halttunen et al. 2018), no significant differences in behavior nor in survival were found between treated and control groups (Gjelland et al. 2014; Halttunen et al. 2018), making it difficult to draw firm conclusions about the relative role of salmon lice itself. Nevertheless, all these studies are based on the use of anti-parasitic drugs. Due to the earlier stated caveats associated with this method, the lack of decisive results in these studies could arguably be related to methodological limitations. Furthermore, this kind of studies only test the effect of treatment against unknown lice intensities on control fish, and thus are not suited to investigate the shape of the relationship between lice and their impact on the host fish. Consequently, it has been suggested that moving from treatment-based to exposure-based studies may be a more suited approach (Vollset et al. 2018).
In this pilot study, we have tested an infestationbased randomized control trial (RCT) as an alternative to the more extended prophylaxis-based approach to investigate the effect of salmon lice on wild, freeswimming sea trout. We have compared survival and habitat preferences between wild sea trout post-smolts either from a control group or from a group artificially infested with salmon lice. The combination of methods presented here (i.e. artificial infestation of wild fish in an area with natural low lice infestation pressure, combined with acoustic telemetry and hydrodynamical modeling) is, to our knowledge, novel in the pursue of quantitative evidence of the impact of salmon lice on sea trout in their natural habitat.

Only one of the end-points analyzed in this pilot study, i.e. differences in salinity preferences as determined by model simulations, showed statistically significant differences between control and artificially infested fish. Besides, limitations on the statistical

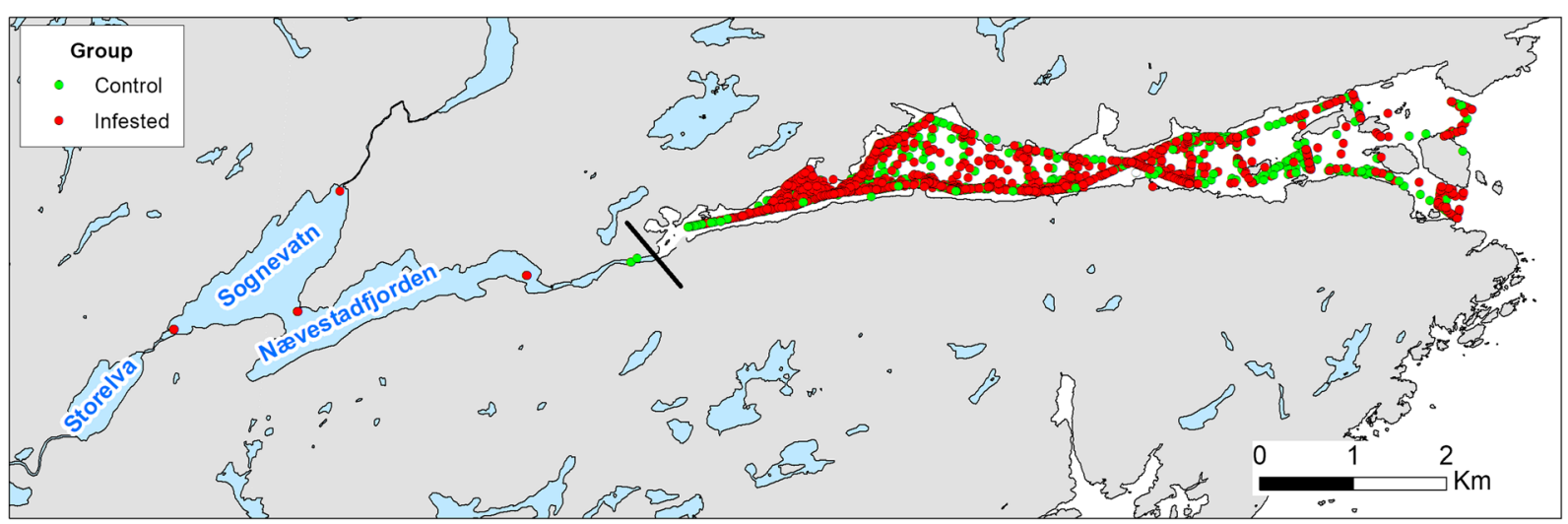

Fig. 3 Trout positions (centres of activity), coloured per group (control and infested). Distance to freshwater was calculated as the linear distance to the black solid line. Positions in freshwater (light-blue areas) were attributed negative distances 

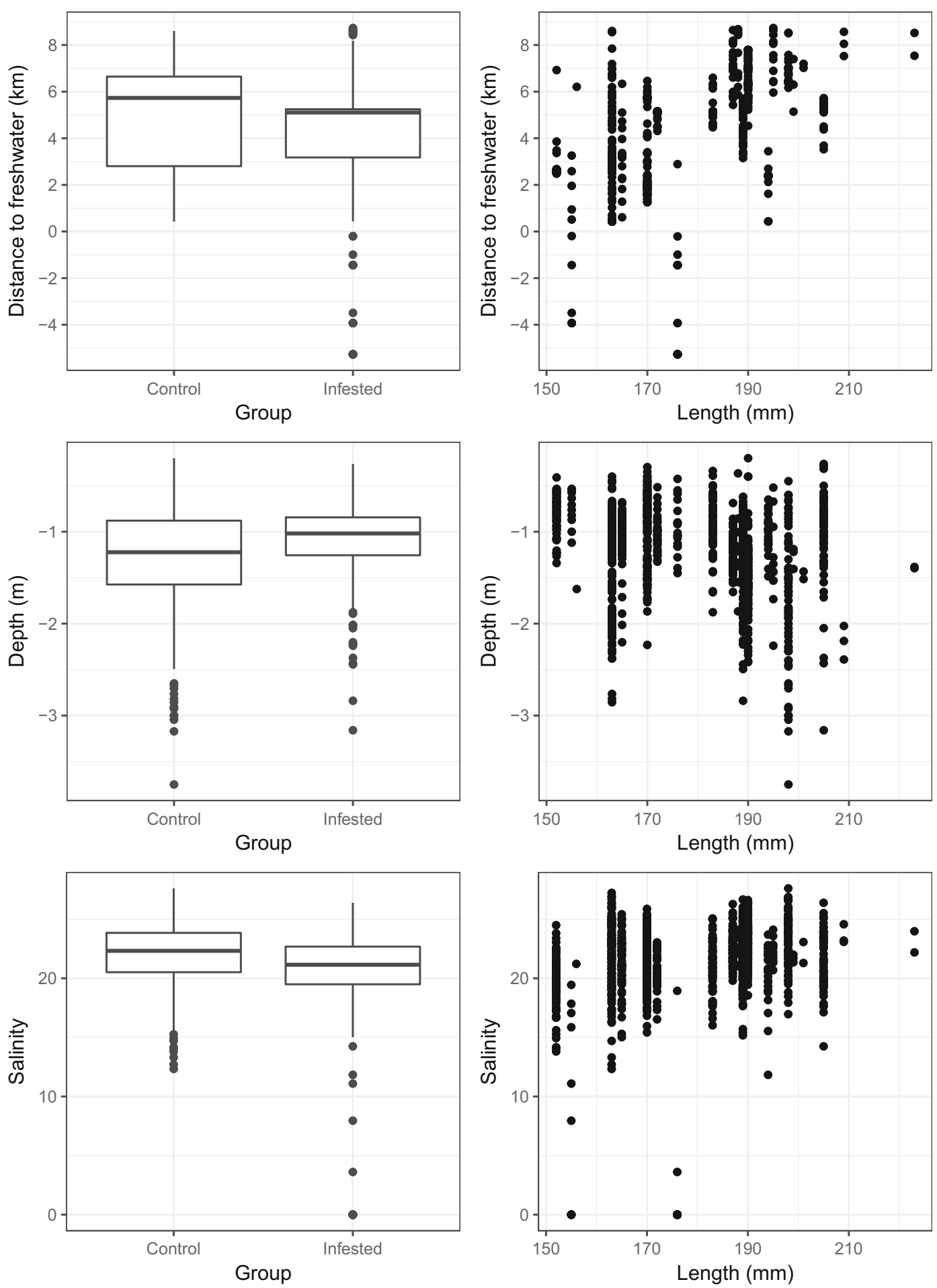

Fig. 4 Mean daily distance to freshwater, mean daily depth and mean daily salinity used of sea trout (Salmo trutta) post-smolts, as a function of group (control, $n=14$ vs infested, $n=14$ ) and body length 
Table 4 Model coefficients $(\beta)$ and corresponding standard errors (SE), t values and significance levels $(P)$, describing the effect of group and body size on mean daily distance to freshwater, mean depth and mean salinity used by sea trout in Sandnesfjord

\begin{tabular}{|c|c|c|c|c|c|c|}
\hline Response & Term & $\beta$ & SE & $\mathrm{DF}$ & $\mathrm{t}$ & $P$ \\
\hline \multirow[t]{3}{*}{ Distance to freshwater } & Intercept & -11.011 & 4.031 & 1021 & -2.732 & 0.006 \\
\hline & Group [Infested] & -1.139 & 0.740 & 25 & -1.539 & 0.136 \\
\hline & Length & 0.090 & 0.022 & 25 & 4.184 & $<0.001$ \\
\hline \multirow[t]{3}{*}{ Depth } & Intercept & -0.305 & 0.618 & 1021 & -0.494 & 0.622 \\
\hline & Group [Infested] & -0.222 & 0.109 & 25 & -2.029 & 0.053 \\
\hline & Length & 0.009 & 0.003 & 25 & 2.676 & 0.013 \\
\hline \multirow{3}{*}{$\begin{array}{l}\text { Salinity } \\
\text { (river and fjord) }\end{array}$} & Intercept & 4.174 & 8.342 & 1021 & 0.500 & 0.617 \\
\hline & Group [Infected] & -2.900 & 1.523 & 25 & -1.903 & 0.069 \\
\hline & Length & 0.097 & 0.045 & 25 & 2.172 & 0.040 \\
\hline \multirow{3}{*}{$\begin{array}{l}\text { Salinity } \\
\text { (only fjord) }\end{array}$} & Intercept & 13.439 & 2.500 & 1000 & 5.376 & 0.000 \\
\hline & Group [Infested] & -1.243 & 0.436 & 25 & -2.854 & 0.009 \\
\hline & Length & 0.048 & 0.014 & 25 & 3.479 & 0.002 \\
\hline
\end{tabular}

power of such a small study (with only 14 fish in each group) were somehow expected. Furthermore, almost one third of the fish was lost from the study area after only 1 week post-release, which severely limited the amount of data available for posterior analyses. Power analysis further confirmed that the limited statistical power of our pilot study was not robust enough to unequivocally demonstrate whether the lack of differences between the groups reflected a real lack of impact from the lice burden, or was rather the result of the low statistical power. Thus, the lack of support for our hypothesis of increased risk of mortality and premature return for artificially infested fish cannot be seen as a proof for the hypothesis being refuted. Regardless, all our results consistently point at the same direction, i.e. towards artificially infested fish showing an altered behavior compared to their control counterparts, which may ultimately result in reduced survival and/ or fitness. We see these results as a support for our idea that this shift in method is the way forward for disentangling and finally quantifying the impact of salmon lice on wild sea trout. However, in order to provide solid quantitative proof of this impact (or lack of), robust study designs which will deliver the necessary statistical power to unequivocally support (or refute) these hypotheses are urgently needed. In the following paragraphs, we share some thoughts about the strengths and limitations of the study design presented here, and further make some recommendations on how to increase the statistical power of future study designs following this approach.
Two important premises for an infestation-based approach to causally explain the effects of salmon lice per se is that $i$ ) all fish should be free for lice by the start of the study, and ii) control fish should remain free from lice during the rest of the study. Lice burdens on wild fish typically remain very low during the whole sea migration period in farm-free areas (Tingley et al. 1997; Schram et al. 1998; Heuch et al. 2002; Rikardsen 2004; Urquhart et al. 2009; Serra-Llinares et al. 2014). We consequently selected Sandnesfjord, situated more than $80 \mathrm{~km}$ away from the closest salmon farm, to conduct our study. Unfortunately, most wild sea trout used in our study carried unexpectedly high lice loads at the moment of capture, circumstance that may have obscured the differences between groups and reduced the effect size (and thus statistical power) of our analysis. Occasional lice outbreaks have previously been described in farm-free areas (Serra-Llinares et al. 2014), probably related to infrequent hydrodynamical conditions, even though these tend to be isolated peaks and to occur only rarely. One possible and safe alternative to find lice-free sea trout by the start of the study could be to capture out-migrating sea trout smolts right before they leave the river on their way out to the sea. Moreover, control fish could be further shielded from lice infestation by use of antiparasitic treatments. However, chemical prophylaxis may have unwelcome side-effects on the fish as well as affect other parasites than sea lice, which may interfere with the results of the study. Also, it has been suggested that some physiological and behavioral 
responses to high salmon lice infestation pressure may be present even before the lice impose osmoregulatory problems (Birkeland and Jakobsen 1997; Gjelland et al. 2014). Thus, prophylaxis treatments preventing the molting of the lice but not the attachment (such as substance EX, Pharmaq, Norway) may still fail to prevent lice-induced behavioral changes (Birkeland and Jakobsen 1997; Gjelland et al. 2014). Sivertsgård et al. (2007) evaluated the effect of salmon lice on i) artificially infested, ii) control and iii) lice-protected (substance EX, Pharmaq, Norway) hatchery-reared sea trout and Atlantic salmon smolts equipped with acoustic transmitters. In their study, no differences in mortality where observed between the three groups during fjord migration for neither species. However, the study extended only over a short time period, and during which period the salmon lice could develop only to the chalimus stage of the life cycle. Independently of whether the chosen design includes or not the treatment of some fish with antiparasitic medication, a proper monitoring of the lice infestation pressure in the study area should be mandatory to detect the potential exposure of the experimental fish to additional lice.

In this pilot study we did not perform individual lice counts on the fish prior to release but rather followed a group-level approach, where the final lice burden on the artificially infested fish was estimated based on lice counts from a reference group. We estimated a final artificial infestation of more than $0.3 \mathrm{lice} / \mathrm{g}$ fish for lice in the infested group. This is regarded as a heavy load with severe consequences for the host (Taranger et al. 2015; Thorstad et al. 2015) and at the same time it is not uncommon to find such infestation levels on wild fish (MacKenzie et al. 1998; Tully et al. 1999; Bjørn et al. 2001; Serra-Llinares et al. 2014; Gargan et al. 2017). The advantage with group-based studies is that only a portion of the fish needs to be handled and inspected for lice after artificial infestation. The drawback, on the other hand, is that any differences observed between infested and control fish can only be attributed to the particular lice burden estimated for the infested group. Alternatively, individual-based studies where each individual fish is examined for lice prior to release and where the whole range of possible lice burdens is represented would be a more suitable approach for describing the shape of the relationship between salmon lice and sea trout mortality (or other life history traits). In this case, especial care should be taken during the manual examination of the fish post-infestation, in order to minimize the risk of removing the delicate newly attached copepodites. Also, little is known about the effect of fish anesthetics on sea lice, and thus potential extra loses of lice due to the sedation of the fish should not be ignored.

The use of acoustic telemetry in this study allowed direct observation of mortality, thus avoiding a total dependence on returns/recaptures, which are often limited and hard to obtain (Skilbrei et al. 2013; Skaala et al. 2014; Vollset et al. 2016). However, nearly $1 / 3$ of the fish in this study rapidly left the study area and were never observed again, severely reducing the amount of data available for analysis and thus limiting the ability of the study to reach statistically significant inferences. Increasing the number of fish released would be the first and most obvious way to bust the statistical power of the study, but it would also entail elevated costs related to the tagging and lice-counting of an elevated number of individuals. Besides, the release of a large number of artificially infested sea trout in an otherwise relatively lice-free area may have ecological and ethical implications that, in any case, should be given proper consideration. Another way to increase our chances of reaching statistically significant inferences would be to expand the temporal and/or spatial coverage of the study. A common caveat of telemetry studies is the limited life-span of acoustic tags due to battery capacity, which may not allow for the detection of returning fish later in the season or even in following years. Other tagging techniques such as PIT tags can unlimitedly extend the duration of the study but are dependent on number or returns/ recaptures. A combination of both techniques could be a good trade-off, so that additional detections gained from PIT tags can add robustness to survival analyses based on telemetry data. Additionally, expanding the spatial coverage of the study would increase the chances of detecting tagged fish and thus increase the amount of information available for analysis. One could, for instance, add additional hydrophones in more remote areas which the fish may be sporadically visiting or even add PIT antennas in other rivers in the system, this way increasing both the temporal and the spatial coverage of the study simultaneously.

Last, the high acoustic coverage of the study area allowed us to observe habitat choice preferences, including depth and salinity, in this pilot study. Indeed, 
infested and smaller fish were found in shallower waters, as well as closer to the estuary area, compared to control fish. By combining 3D fish positioning with a state-of-the-art hydrodynamic model, we were able to further demonstrate that the observed differences in habitat use reflect a preference for lower salinities for infested fish, illustrating that this combination of methods can be of excellent value for understanding more detailed behavioral responses, e.g. beyond the mere observation of premature return to freshwater. Behavioral restrictions caused by high parasite load, such as dependency for low salinity waters, can result in the loss of foraging opportunity and efficiency (Birkeland 1996), which, in turn, may entail a reduction in growth, survival, and reproductive potential for the host fish (Birkeland 1996; Wells et al. 2007; Fjørtoft et al. 2014).

The impacts of sea lice on wild salmonids is and will continue to be an important constrain for the development of a sustainable marine aquaculture industry. Thus, studies that aim to quantify the impact of salmon lice in the wild are urgently needed. Our study showed promising results from the combination of an infestationbased RCT in a fjord with low density of salmon lice, the use of acoustic telemetry and the use of detailed 3D hydrodynamical modeling for analyzing the impact of salmon lice on wild, free swimming sea trout. We recommend further studies with larger data sets over a number of years and under different environmental conditions following this innovative approach. Some suggested improvements to increase the statistical power of future studies would be to $i$ ) increase the number of tagged fish to reach a minimum required sample size, ii) catch out-migrating sea trout smolts before they enter the sea, and iii) expand the spatial and/or temporal coverage of the study, for instance by combining acoustic telemetry with PIT tagging. This is likely to provide new and valuable quantitative evidence on the effect of salmon lice on sea trout in the wild.

\footnotetext{
Acknowledgments The work was funded by internal grants from Institute of Marine Research, Norway, project no. 14650. The research presented in this manuscript been approved by the Norwegian Animal Research Authority, FOTS ID 860. We acknowledge Bjørnar Skjold, at the Institute of Marine Research (IMR), for supplying the copepodids used in the study. We also thank Anders Jelmert for his technical assistance in the field and Esben Moland Olsen (IMR), Even Moland (IMR) and Tormod Haraldstad (NIVA), for sharing their expertise on the study area.
}

Open Access This article is distributed under the terms of the Creative Commons Attribution 4.0 International License (http:// creativecommons.org/licenses/by/4.0/), which permits unrestricted use, distribution, and reproduction in any medium, provided you give appropriate credit to the original author(s) and the source, provide a link to the Creative Commons license, and indicate if changes were made.

\section{References}

Albretsen J, Sperrevik AK, Staalstrøm A, Sandvik AD, Vikebø F \& Asplin L (2011) NorKyst-800 report no. 1 - user manual and technical descriptions. Fisken og Havet 2/2011, Institute of Marine Research

Asplin L, Johnsen IA, Sandvik AD, Albretsen J, Sundfjord V, Aure J, Boxaspen KK (2014) Dispersion of salmon lice in the Hardangerfjord. Mar Biol Res 10:216-225

Barlaup BT, Gabrielsen S-E, Løyland J, Schläppy M-L, Wiers T, Vollset KW, Pulg U (2013) Trap design for catching fish unharmed and the implications for estimates of sea lice (Lepeophtheirus salmonis) on anadromous brown trout (Salmo trutta). Fish Res 139:43-46

Birkeland K (1996) Consequences of premature return by sea trout (Salmo trutta) infested with the salmon louse (Lepeophtheirus salmonis Krøyer): migration, growth, and mortality. Can J Fish Aquat Sci 53:2808-2813

Birkeland K, Jakobsen PJ (1997) Salmon lice, Lepeophtheirus salmonis, infestation as a causal agent of premature return to rivers and estuaries by sea trout, Salmo trutta, juveniles. Environ Biol Fish 49:129-137

Bjorn P, Finstad B (1997) The physiological effects of salmon lice infection on sea trout post smolts. Nord J Freshw Res 73:60-72

Bjørn P, Finstad B, Kristoffersen R (2001) Salmon lice infection of wild sea trout and Arctic char in marine and freshwaters: the effects of salmon farms. Aquac Res 32:947-962

Bjørn PA, Sivertsgård R, Finstad B, Nilsen R, Serra-Llinares RM, Kristoffersen R (2011) Area protection may reduce salmon louse infection risk to wild salmonids. Aquac Environ Interact 1:233-244

Butler J, Walker A (2006) Characteristics of the sea trout Salmo trutta L. stock collapse in the river ewe (wester Ross, Scotland) in 1988-2001. In: Sea trout: biology, conservation and management, pp 45-59

Costello MJ (2009) How sea lice from salmon farms may cause wild salmonid declines in Europe and North America and be a threat to fishes elsewhere. Proc R Soc Lond B Biol Sci 276: 3385-3394

Dawson L (1998) The physiological effects of salmon lice (Lepeophtheirus salmonis) infections on returning postsmolt sea trout (Salmo trutta L.) in western Ireland, 1996. ICES J Mar Sci 55:193-200

Espeland SH, Albretsen J, Olsen EM, Bodvin T (2015) Modelling drift of pelagic offspring: the importance of egg surveys in providing a realistic model initialization. ICES J Mar Sci 72: $2578-2589$

Fjørtoft HB, Borgstrøm R, Skaala Ø (2014) Differential changes in growth patterns of anadromous brown trout and Atlantic 
salmon from the river Etneelva over a 25-year period. Mar Biol Res 10:301-307

Fjørtoft HB, Besnier F, Stene A, Nilsen F, Bjørn PA, Tveten AK et al (2017) The Phe362Tyr mutation conveying resistance to organophosphates occurs in high frequencies in salmon lice collected from wild salmon and trout. Sci Rep 7(1):14258

Forseth T, Barlaup BT, Finstad B, Fiske P, Gjøsæter H, Falkegård $M$ et al (2017) The major threats to Atlantic salmon in Norway. ICES J Mar Sci 74:1496-1513

Gargan P, Tully O, Poole W (2003) Relationship between sea lice infestation, sea lice production and sea trout survival in Ireland, 1992-2001. In: Salmon at the edge, vol 10, pp 119-135

Gargan P, Roche W, Forde G, Ferguson A (2006) Characteristics of the sea trout (Salmo trutta L.) stocks from the Owengowla and Invermore fisheries, Connemara, Western Ireland, and recent trends in marine survival. In: sea trout: biology. In: Conservation and management, pp 60-75

Gargan P, Forde G, Hazon N, Russell D, Todd C (2012) Evidence for sea lice-induced marine mortality of Atlantic salmon (Salmo salar) in western Ireland from experimental releases of ranched smolts treated with emamectin benzoate. Can J Fish Aquat Sci 69:343-353

Gargan P, Kelly F, Shephard S, Whelan K (2016) Temporal variation in sea trout Salmo trutta life history traits in the Erriff River, western Ireland. Aquac Environ Interact 8:675-689

Gargan PG, Shephard S, MacIntyre C (2017) Assessment of the increased mortality risk and population regulating effect of sea lice (Lepeophtheirus salmonis) from marine salmon farms on wild sea trout in Ireland and Scotland. In: Harris G (ed) Sea trout: Science \& Management. Proceedings of the 2nd International Sea trout symposium, pp 507-522

Gjelland KØ, Serra-Llinares RM, Hedger RD, Arechavala-Lopez P, Nilsen R, Finstad B et al (2014) Effects of salmon lice infection on the behaviour of sea trout in the marine phase. Aquac Environ Interact 5(3):221-233

Halttunen E, Gjelland KØ, Hamel S, Serra-Llinares RM, Nilsen R, Arechavala-Lopez P et al (2018) Sea trout adapt their migratory behaviour in response to high salmon lice concentrations. J Fish Dis 41(6):953-967

Hamre LA, Glover KA, Nilsen F (2009) Establishment and characterisation of salmon louse (Lepeophtheirus salmonis (Krøyer 1837)) laboratory strains. Parasitol Int 58:451-460

Hatton-Ellis M, Hay D, Walker A, Northcott S (2006) Sea lice Lepeophtheirus salmonis infestations of post-smolt sea trout in loch Shieldaig, wester Ross, 1999-2003. In: sea trout: biology. In: Conservation and management, pp 372-376

Helland IP, Uglem I, Jansen PA, Diserud OH, Bjørn PA, Finstad B (2015) Statistical and ecological challengesof monitoring parasitic salmon lice infestationsin wild salmonid fish stocks. Aquac Environ Interact 7(3):267-280

Heuch P, Knutsen J, Knutsen H, Schram T (2002) Salinity and temperature effects on sea lice over-wintering on sea trout (Salmo trutta) in coastal areas of the Skagerrak. J Mar Biol Assoc U K 82:887-892

Jackson D, Cotter D, ÓMaoiléidigh N, O'Donohoe P, White J, Kane F et al (2011) An evaluation of the impact of early infestation with the salmon louse Lepeophtheirus salmonis on the subsequent survival of outwardly migrating Atlantic salmon, Salmo salar L., smolts. Aquaculture 320:159-163
Krkošek M, Revie CW, Gargan PG, Skilbrei OT, Finstad B, Todd CD (2013) Impact of parasites on salmon recruitment in the Northeast Atlantic Ocean. Proc R Soc Lond B Biol Sci 280: 20122359

MacKenzie K, Longshaw M, Begg G, McVicar A (1998) Sea lice (Copepoda: Caligidae) on wild sea trout (Salmo trutta L.) in Scotland. ICES J Mar Sci 55:151-162

Middlemas S, Fryer R, Tulett D, Armstrong J (2013) Relationship between sea lice levels on sea trout and fish farm activity in western Scotland. Fish Manag Ecol 20:68-74

Müller M, Homleid M, Ivarsson K, Køltzow M, Lindskog M, Midtbø K, Andrae U, Aspelien T, Berggren L, Bjørge D, Dahlgren P, Kristiansen J, Randriamampianina R, Ridal M, Vignes O (2015) 0: AROME - MetCoOp: a Nordic convective scale operational weather prediction model. Weather Forecast 32(2):609-627

Pert C, Raffell J, Urquhart K, Weir S, Kantola K, Bricknell I (2009) The pathogen burden of early returning sea trout(Salmo trutta L.) infected with Lepeophtheirus salmonis(Kroyer, 1837), in the river Shieldaig, Scotland. Bull Eur Assoc Fish Pathol 29:210-216

Poole W, Whelan K, Dillane M, Cooke D, Matthews M (1996) The performance of sea trout, Salmo trutta L., stocks from the Burrishoole system western Ireland, 1970-1994. Fish Manag Ecol 3:73-92

Poole W, Nolan D, Tully O (2000) Modelling the effects of capture and sea lice [Lepeophtheirus salmonis (Krøyer)] infestation on the cortisol stress response in trout. Aquac Res 31:835-841

Rikardsen A (2004) Seasonal occurrence of sea lice Lepeophtheirus salmonis on sea trout in two north Norwegian fjords. J Fish Biol 65:711-722

Schram T, Knutsen J, Heuch P, Mo T (1998) Seasonal occurrence of Lepeophtheirus salmonis and Caligus elongatus (Copepoda: Caligidae) on sea trout (Salmo trutta), off southern Norway. ICES J Mar Sci 55:163-175

Serra-Llinares RM, Nilsen R, Uglem I, Arechavala-Lopez P, Bjørn P-A, Noble C (2013) Post-escape dispersal of juvenile Atlantic cod Gadus morhua from Norwegian fish farms and their potential for recapture. Aquac Environ Interact 3:107-116

Serra-Llinares RM, Bjørn PA, Finstad B, Nilsen R, Harbitz A, Berg M, Asplin L (2014) Salmon lice infection on wild salmonids in marine protected areas: an evaluation of the Norwegian 'National Salmon Fjords'. Aquac Environ Interact 5:1-16. https://doi.org/10.3354/aei00090

Serra-Llinares RM, Bjørn PA, Finstad B, Nilsen R, Asplin L (2016) Nearby farms are a source of lice for wild salmonids: a reply to Jansen et al. (2016). Aquac Environ Interact 8:351-356

Shephard S, MacIntyre C, Gargan P (2016) Aquaculture and environmental drivers of salmon lice infestation and body condition in sea trout. Aquac Environ Interact 8:597-610

Simpfendorfer CA, Heupel MR, Hueter RE (2002) Estimation of short-term centers of activity from an array of omnidirectional hydrophones and its use in studying animal movements. Can J Fish Aquat Sci 59:23-32

Sivertsgård R, Thorstad EB, Økland F, Finstad B, Bjørn PA, Jepsen N, Nordal T, McKinley RS (2007) Effects of salmon lice infection and salmon lice protection on fjord migrating Atlantic salmon and brown trout post-smolts. Hydrobiologia $582: 35-42$ 
Skaala Ø, Kålås S, Borgstrøm R (2014) Evidence of salmon liceinduced mortality of anadromous brown trout (Salmo trutta) in the Hardangerfjord, Norway. Mar Biol Res 10:279-288

Skilbrei O, Finstad B, Urdal K, Bakke G, Kroglund F, Strand R (2013) Impact of early salmon louse, Lepeophtheirus salmonis, infestation and differences in survival and marine growth of sea-ranched Atlantic salmon, Salmo salar L., smolts 1997-2009. J Fish Dis 36:249-260

Taranger GL, Karlsen Ø, Bannister RJ, Glover KA, Husa V, Karlsbakk E et al (2015) Risk assessment of the environmental impact of Norwegian Atlantic salmon farming. ICES J Mar Sci 72:997-1021

Thorstad EB, Todd CD, Uglem I, Bjørn PA, Gargan PG, Vollset KW et al (2015) Effects of salmon lice Lepeophtheirus salmonis onwild sea trout Salmo trutta - a literature review. Aquac Environ Interact 7(2):91-113

Tingley G, Ives M, Russell I (1997) The occurrence of lice on sea trout (Salmo trutta L.) captured in the sea off the east Anglian coast of England. ICES J Mar Sci 54:1120-1128

Tjomsland T \& Kroglund F (2010) Modellering av strøm og saltholdighet i Sandnesfjorden ved Risør. NIVA Rapport Vol LNR 6049-2010

Tully O, Whelan K (1993) Production of nauplii of Lepeophtheirus salmonis (Krøyer)(Copepoda: Caligidae) from farmed and wild salmon and its relation to the infestation of wild sea trout (Salmo trutta L.) off the west coast of Ireland in 1991. Fish Res 17:187-200

Tully O, Gargan P, Poole W, Whelan K (1999) Spatial and temporal variation in the infestation of sea trout (Salmo trutta L.) by the caligid copepod Lepeophtheirus salmonis (Krøyer) in relation to sources of infection in Ireland. Parasitology 119:41-51

Urquhart K, Pert CC, Fryer RJ, Cook P, Weir S, Kilburn R et al (2009) A survey of pathogens and metazoan parasites on wild sea trout (Salmo trutta) in Scottish waters. ICES J Mar Sci 67:444-453

Vollset KW, Barlaup BT, Skoglund H, Normann ES, Skilbrei OT (2014) Salmon lice increase the age of returning Atlantic salmon. Biol Lett 10:20130896

Vollset KW, Krontveit RI, Jansen PA, Finstad B, Barlaup BT, Skilbrei OT et al (2016) Impacts of parasites on marine survival of Atlantic salmon: a meta-analysis. Fish Fish 17: 714-730

Vollset KW, Dohoo I, Karlsen Ø, Halttunen E, Kvamme BO, Finstad B, Wennevik V, Diserud OH, Bateman A, Friedland KD, Mahlum S, Jørgensen C, Qviller L, Krkošek M, Åtland $\AA$, Barlaup BT (2018) Disentangling the role of sea lice on the marine survival of Atlantic salmon. ICES J Mar Sci 75: $50-60$

Wells A, Grierson CE, Marshall L, MacKenzie M, Russon IJ, Reinardy H et al (2007) Physiological consequences of "premature freshwater return" for wild sea-run brown trout (Salmo trutta) postsmolts infested with sea lice (Lepeophtheirus salmonis). Can J Fish Aquat Sci 64:13601369. https://doi.org/10.1139/f07-107

Zuur AF, Ieno EN, Walker NJ, Saveliev AA, Smith GM (2009) Mixed effects models and extensions in ecology with R. Springer, New York 